\title{
Bioinformatic screening of human ESTs for differentially expressed genes in normal and tumor tissues Abdel Aouacheria* ${ }^{* 1,3}$, Vincent Navratil ${ }^{\dagger 1}$, Audrey Barthelaix ${ }^{2}$, Dominique Mouchiroud ${ }^{1}$ and Christian Gautier ${ }^{1}$
}

\begin{abstract}
Address: 'Laboratoire de Biométrie et Biologie Evolutive, CNRS UMR 5558, Université Claude Bernard Lyon 1, 69622 Villeurbanne Cedex, France, ${ }^{2}$ Aptanomics, 181-203, avenue Jean Jaurès 69007 Lyon, France and ${ }^{3}$ Current address: Apoptosis and Oncogenesis Laboratory, IBCP, UMR 5086 CNRS-UCBL, IFR 128, Lyon, France

Email: Abdel Aouacheria* - a.aouacheria@ibcp.fr; Vincent Navratil - navratil@biomserv.univ-lyon1.fr; Audrey Barthelaix - audrey.barthelaix@aptanomics.com; Dominique Mouchiroud - mouchi@biomserv.univ-lyon1.fr; Christian Gautier - cgautier@biomserv.univ-lyon1.fr

* Corresponding author †Equal contributors
\end{abstract}

Published: 26 April 2006

BMC Genomics2006, 7:94 doi:10.1/86/147|-2164-7-94
Received: 14 October 2005

Accepted: 26 April 2006

This article is available from: http://www.biomedcentral.com/147I-2/64/7/94

(c) 2006Aouacheria et al; licensee BioMed Central Ltd.

This is an Open Access article distributed under the terms of the Creative Commons Attribution License (http://creativecommons.org/licenses/by/2.0), which permits unrestricted use, distribution, and reproduction in any medium, provided the original work is properly cited.

\begin{abstract}
Background: Owing to the explosion of information generated by human genomics, analysis of publicly available databases can help identify potential candidate genes relevant to the cancerous phenotype. The aim of this study was to scan for such genes by whole-genome in silico subtraction using Expressed Sequence Tag (EST) data.

Methods: Genes differentially expressed in normal versus tumor tissues were identified using a computer-based differential display strategy. Bcl-xL, an anti-apoptotic member of the Bcl-2 family, was selected for confirmation by western blot analysis.

Results: Our genome-wide expression analysis identified a set of genes whose differential expression may be attributed to the genetic alterations associated with tumor formation and malignant growth. We propose complete lists of genes that may serve as targets for projects seeking novel candidates for cancer diagnosis and therapy. Our validation result showed increased protein levels of Bcl-xL in two different liver cancer specimens compared to normal liver. Notably, our EST-based data mining procedure indicated that most of the changes in gene expression observed in cancer cells corresponded to gene inactivation patterns. Chromosomes and chromosomal regions most frequently associated with aberrant expression changes in cancer libraries were also determined.

Conclusion: Through the description of several candidates (including genes encoding extracellular matrix and ribosomal components, cytoskeletal proteins, apoptotic regulators, and novel tissuespecific biomarkers), our study illustrates the utility of in silico transcriptomics to identify tumor cell signatures, tumor-related genes and chromosomal regions frequently associated with aberrant expression in cancer.
\end{abstract}




\section{Background}

Large-scale transcriptome analysis of genes that are differently expressed in tumor tissues compared to their normal counterparts is an important route to the identification of candidates that could play a role in human malignancies. A number of techniques, ranging from differential display and nucleic acid subtraction to serial analysis of gene expression, expression microarrays and gene chips, have been used to the discovery of such aberrantly expressed cancer-related genes [1]. The well-established differential screening technology, that allows for the simultaneous comparison of multiple gene expression levels between two samples differing in tissue type and pathological state, has been the more extensively applied. This simple and powerful method could be performed either experimentally or, since late 1999, digitally using expression databases. The computer-based differential display methodology, also referred to as 'in silico subtraction' or 'electronic northern' [2-7], could identify transcripts preferentially expressed or repressed in the tumor context by comparing cancerous libraries (present in publicly available databases) against the remaining libraries. Strikingly, only few attempts were made to apply in silico transcriptomics to genome-wide and multi-tissue screening of cancer genes [8-10]. Thus, given the continuous expansion of the EST databases, both in terms of sequence and source diversity, updated and independent transcriptomic analyses are permanently needed.

In this study, we mined EST libraries for genes differentially expressed in normal and tumor tissues by using a novel computational approach, with the assumption that both the up- and down-regulated pools might contain genes involved in tumorigenesis. This strategy identified differential expression profiles and cancer candidate genes which may be useful in future cancer research. Higher expression of the anti-apoptotic protein Bcl-xL in liver cancer specimens compared to normal liver was confirmed by immunoblot analysis. Strikingly, we found that most cancer-associated changes in gene expression corresponded to genes that were actually downregulated or repressed. The chromosomes and chromosomal regions most frequently associated with aberrant expression changes in tumor versus normal cells were also determined. This analysis suggests that, although genes differentially expressed in cancerous libraries are distributed throughout the genome, chromosomal 'hot spots' of candidate genes could be identified.

\section{Results \\ Identification of differentially expressed genes between normal and cancer tissues}

Genes differentially expressed in tumor libraries compared to their normal counterparts are likely to play important roles in cancer etiology or could constitute rel- evant genetic markers for cancer diagnosis. Here, we have performed in silico differential display to identify novel and known cancer-associated genes by comparing all the libraries representing tumors to the corresponding normal libraries for each tissue type. Details about the data mining procedures are presented in Table 1 . In order to be able to compare expression levels between normal and tumor state, we compared EST counts from non-normalized, non-subtracted cDNA libraries. To overcorrect for the false positive rate, we decided to perform the highly conservative Bonferroni correction. Using this procedure, a total of 673 genes showed differential expression in tumor versus normal libraries by a factor of 10 or higher (Additional File 1: 'Upregulated candidates complete list', and Additional File 2: 'Downregulated candidates complete list'), with about one third being up-regulated (299) and the remaining being down-regulated (539). The in silico subtraction also resulted in the identification of 181 and 336 genes predicted to be present or absent in the tumor types compared to normal tissues, respectively. Because these EST clusters were identified either in normal or tumor libraries, it was not possible to derive their expression ratio, so we decided to present them as separated tables (Additional File 3: 'Tumor specific candidates complete list', and Additional File 4: 'Normal specific candidates complete list'). However, these two groups of genes have been fused to the 'up-regulated' and 'downregulated' pools in the subsequent analyses. All in all, a sum of 112 novel transcripts was also found (i.e. sequences for which no description was available at the time of the study). Noteworthy, in silico subtraction identified $14.5 \%(154 / 1060)$ previously studied genes involved in oncogenesis, based on a list of $\sim 2500$ genes compiled as previously described [11]. Since the fraction of such reference genes in our initial data set was $7.5 \%$ (2401/31800), our data mining protocol expectedly lead to a significant enrichment in cancer genes ( $\mathrm{p}$ value $=2.2$ 10-16; exact Fisher test). These previously characterized and well-studied genes include the p57KIP2 and p19INK4d cyclin inhibitors, and the ras-GAP, $c$-fos, ret and myc oncogenes. Last, in order to independently verify the validity of the EST-based tissue profiles, SAGE data were used to give

Table I: Overview of the EST-based data mining strategy. Screening for differentially expressed genes between normal and cancer tissues. EST counts in each analytical step. Total number of EST clusters in each class (upregulated, downregulated, tumor-specific or absent in tumors) was determined after Bonferroni corrected exact Fisher test.

\begin{tabular}{ll}
\hline Total RNA (Ensembl) & $\sim 31,800$ \\
Total ESTs (after clustering) & $\sim 3.3 \quad 10^{6}$ \\
Total clusters & $26,60 \mathrm{I}$ \\
Total up-regulated EST clusters & 227 \\
Total down-regulated EST clusters & 473 \\
Total EST clusters specific to tumors & 173 \\
Total EST clusters absent in tumors & 308
\end{tabular}


an indication of the tissue distribution of our transcripts in normal tissues. While SAGE results specified by tissue type converged with the analysis of ESTs for 65,4\% (197/ $301), 53,9 \%(91 / 169)$, and 53,2 \% (93/171) of the examined hits in the 'down', 'up' and 'normal-specific' groups respectively, i.e. precisely in the classes where an expression in the normal condition was expected, this percentage decreased to $37,7 \%(46 / 122)$ for the 'tumor-specific' group of transcripts.

\section{Cancer candidate gene analysis}

The first general observation that could be made from our results is that a same gene could be either up-regulated or repressed according to the tumor cell type, allowing identification of tissue-specific gene expression profiles in tumor versus normal cells. For instance, among the set of candidates with differential expression in cancer, we observed a massive down-regulation of several collagen alpha chain genes (but not beta chain genes) in various tumor tissues, including decreased expression of collagen alpha 2(I) (also termed col1A2) in skin, placenta, testis, eye and bone (see Figure 1). Interestingly, col1A2 has been reported as a tumor suppressor gene that could inhibit rasinduced oncogenic transformation $[12,13]$. Apart from collagens, other types of proteins that could be used as useful biomarkers include cytokeratins (CK). CK are particularly interesting epithelia specific intermediate filaments because their degradation gives rise to soluble fragments, measurable in the blood of patients and capable of cancer monitoring [14]. Our results show that a total of 13 CK genes were differentially expressed between normal and malignant cells in 9 different tissues (Figure 1), allowing tissue-specific expression profiling (e.g. specific expression of CK 5, 13 and 16 in tumor brain). Additionally, in line with previous microarray data [15], we found that hair-specific type II keratin was overexpressed in breast tumors compared to normal breast. We further determined that over the 190 genes which displayed aberrant expression in more than one tissue, 131 were "deregulated" in the same way (either up- or down, Figure 2 and Additional File 5: 'Consistent candidates in multiple tissues'). Included in this list of 'consistent' candidates are 13 transcripts encoding different ribosomal components, in accordance with the increasing body of evidence from the literature that correlates changes in the protein synthesis machinery with cancer [16-18]. Specific signatures for ribosomal genes could be determined, e.g. downregulation of the genes encoding 60S ribosomal L37, L38 and L44 in libraries prepared from tumor skin and tumor blood, whereas placental cancer libraries appear to be specifically enriched in transcripts encoding $40 S$ ribosomal S2, S3 and S17. As depicted in Figure 3 (for the full data set, see Additional File 6: 'Tissue specific candidates'), some genes display a tissue-specific pattern of differential expression in tumor types, thus making them candidates for specific diagnostic markers. Among these 114 genes differentially expressed in only one tissue are 14-3-3 sigma in brain tumors and Bnip $3 \mathrm{~L}$ in blood. This latter gene, belonging to the $\mathrm{Bcl}-2$ family of apoptotic regulators, has been described as a potential tumor suppressor $[19,20]$. Last, it is worth noting that a novel member of the methyltransferase enzyme family (ENST00000270172), that contains clear transcriptional repressors $[21,22]$, was found to be specifically overexpressed in placental tumors.

Taken together, these results suggest that EST data could be successfully mined to provide digital profiles of differential gene expression at the full genome level between normal and cancerous tissues. Our lists of transcriptional signatures might help to select candidate markers in cancer genetics or potential targets for therapy.

\section{Increased expression of $B c l-x L$ in liver tumors}

Bcl-2 family member Bcl-xL (Bcl2-associated X membrane protein) was selected for confirmation by immunoblotting due to its plausible biological role in cancer susceptibility. Moreover, both EST and SAGE results indicated that Bcl-xL was poorly expressed in normal liver, while abundant in other tissues (both normal and cancerous, data not shown), suggesting that this apoptotic regulator could constitute a good marker for liver cancer progression. As depicted in Figure 4, western blot analysis confirmed overexpression of $\mathrm{Bcl}-\mathrm{xL}$ in a subset of human liver cancer specimens (hepatocellular carcinoma, adenocarcinoma but not cholangiocellular carcinoma) compared to normal liver (and placenta).

\section{Identification of chromosome locations of differential gene expression in cancer}

We next sought to analyze the chromosomal distribution of the genes which were over-expressed or repressed in tumor tissues. To this end, we mapped the previously identified genes showing significant differential expression between normal and tumor tissues along human chromosomes according to their banding, in order to build cancer-oriented transcriptome maps. To avoid possible biases due to chromosome length (e.g. chromosome $\mathrm{Y}$ as an obvious case) or different chromosomal gene densities, we computed the percentage of candidate genes against the total number of genes present on a particular chromosome or banding (see Table 2).

First, our results show that some chromosomes appear to be more active than others (Table 2A), with, for instance, chromosomes 15, 19 and Y being rarely involved in cancer-related gene expression changes compared to chromosomes 4 and 6 . As expected from the results of Table 1, most chromosomal regions associated with changes in expression levels actually correspond to gene inactivation 


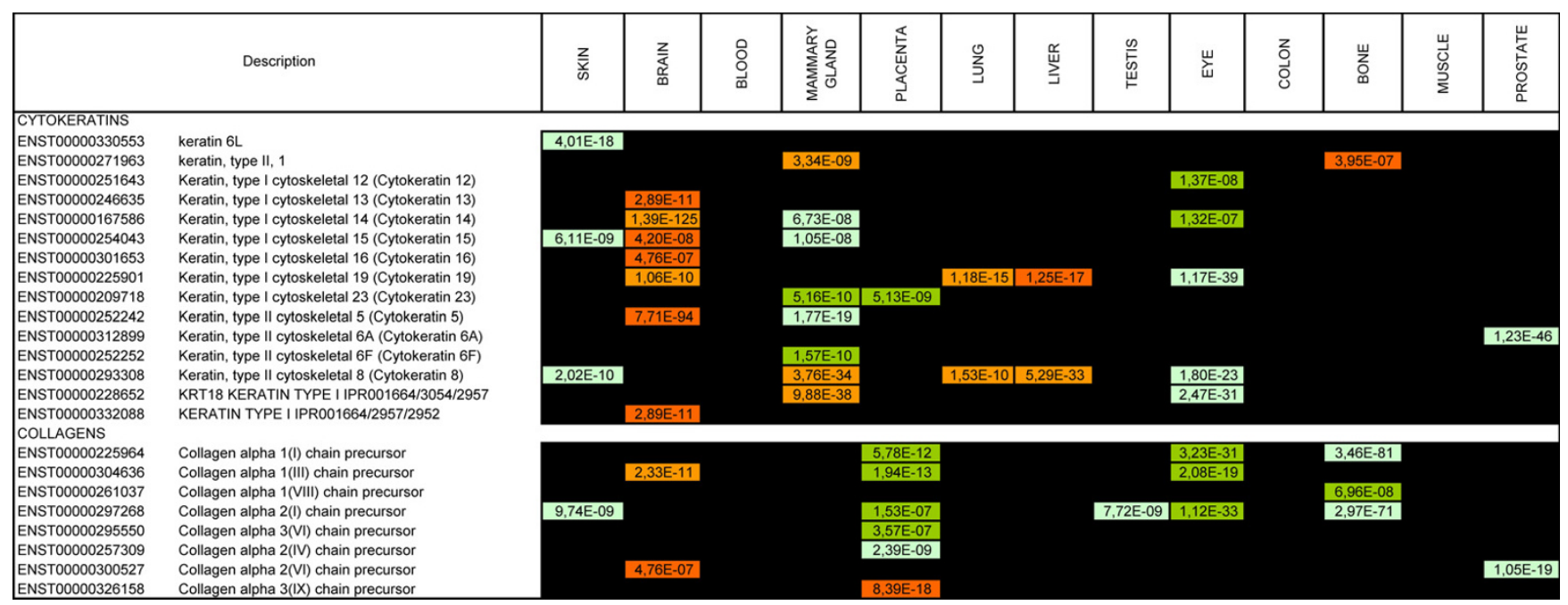

Figure I

Patterns of differential expression for collagen and cytokeratin genes in multiple normal and tumor tissues.

The data are shown in a table format, in which rows represent individual genes and columns represent individual normal tissue. The color in each cell reflects the differential expression level of the corresponding gene in a particular tissue. A four color code was used to represent gene induction and repression in cancer libraries (dark green: 'normal-specific', i.e. not expressed in tumor libraries; light green: downregulated in tumor libraries; orange: upregulated in tumor libraries; red: 'tumor-specific'). If there was no significant change in gene expression between normal and tumor libraries or in case of missing/excluded data, the gene was given in a black color. The number inside the colored cells indicates the statistical significance $(p$-value $<0.0 \mathrm{l}$ after Bonferroni correction). See additional information for the full data.

patterns in cancer cells (373 up-regulated versus 744 down-regulated hits), striking examples of cancer-associated inactivation of gene expression being chromosome 17 and chromosome 3 . While most tissues (14/16) were clearly subject to these cancer-associated gene inactivation patterns (especially lung, eye, colon, prostate and stomach), two tissues (tumor blood and liver) did not follow this trend. Chromosomal regions displaying at least five hits were further listed and this rough analysis was sufficient to detect 11 and 29 regions of clustering of up- and down-regulated genes, respectively (Table 2B). We found previously identified chromosomal regions associated with either tumor amplicon (e.g. 12q13) or deleted (e.g. $11 \mathrm{p} 15)$ regions in tumors [23-26]. Interestingly, some of the chromosomal locations which were identified show tissue specificity, e.g. 12q13.3 in muscle. Moreover, in some cases, candidate genes could be contiguous or clustered in limited banding intervals. For instance, $19 \mathrm{q} 13$ is associated in tumor tissues of placental origin with complete extinction of eight clustered genes, namely pregnancy-specific beta-1-glycoproteins PSG-1, -2, -3, -4, -5, $6,-9$ and -11 . These genes belonging to the carcinoembryonic antigen family encode the major placental proteins found in maternal circulation during pregnancy $[27,28]$.

In conclusion, in addition to providing differential expression profiles for individual genes, our EST-based procedure identified discrete regions on specific chromo- somes that are enriched in genes deregulated in cancer libraries.

\section{Discussion}

Owing to advances in biotechnology and bioinformatics, researchers can now capture "molecular portraits" of various particular cancers using gene chips or SAGE data. These methods provide information on tens of thousands of genes simultaneously, and some variations in genes might be directly related to the cancer phenotype $[1,29]$. As multi-dimensional analysis of EST data is analogous to microarray experiments, we used the virtual differential display methodology to identify genes differentially expressed in normal versus tumor tissues. Our comprehensive approach gives an overview of numerous candidate genes which may be useful as improved biomarkers for diagnosis or as targets for developing novel treatment methods. For instance, EST-based formulation of collagen, integrin or cytokeratin expression profiles may have potential as a diagnostic aid for the detection of both tumor formation and development. Noteworthy, for discovery of tumor-associated molecules, it may be beneficial to use a combination of various digital differential display procedures and experimental data on gene expression. This is illustrated by the identification of prostatespecific Ets factor as a novel marker for breast cancer both computationally $[8,30]$ (and this study) and experimentally [30-32]. 


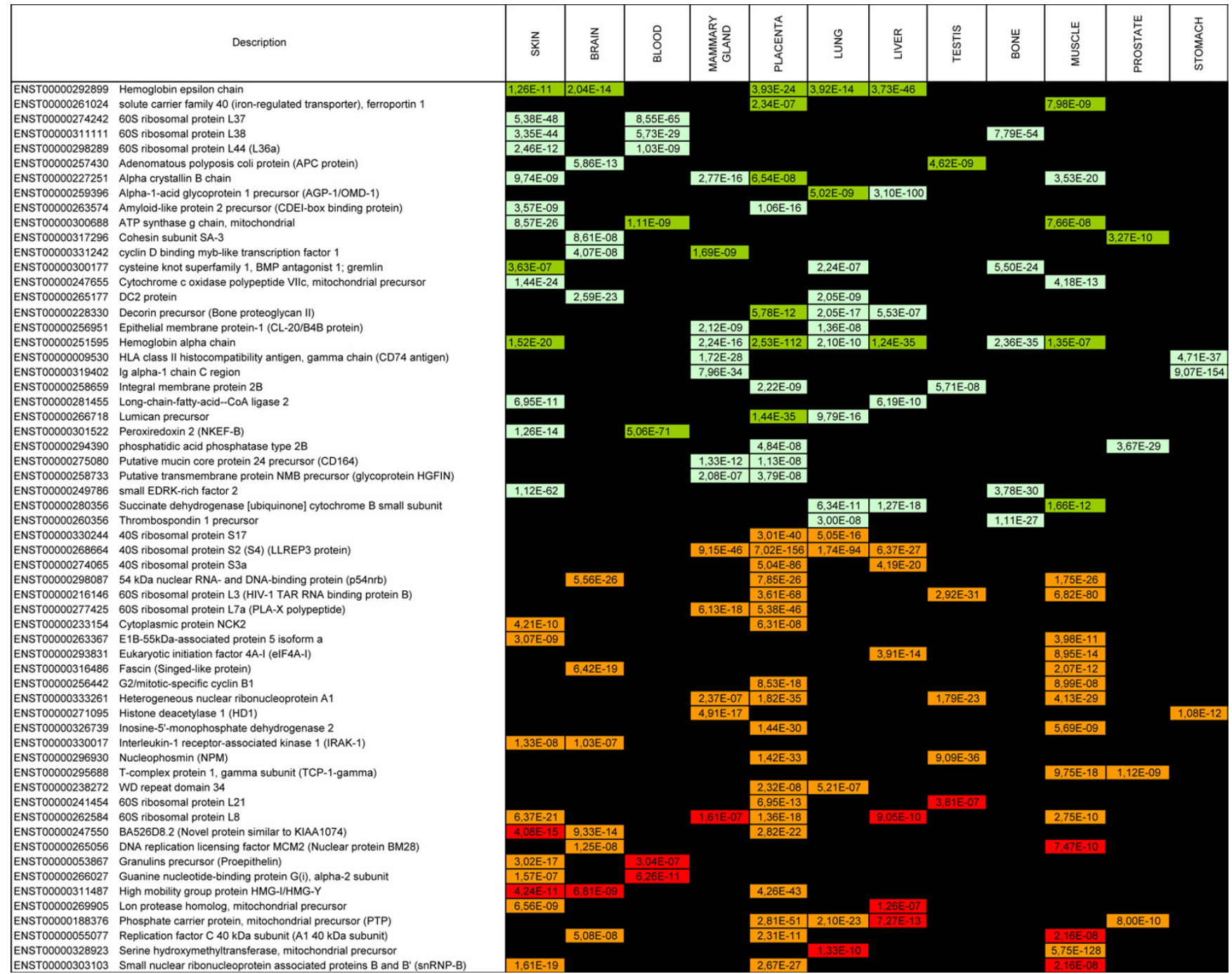

\section{Figure 2}

Genes whose transcripts varied significantly and consistently in abundance in at least two different tissues.

Thirty genes were selected in each class of differential expression (upregulated, downregulated, tumor-specific or absent in tumors). The results are shown for twelve tissues. The legend is the same as in Figure I. See additional information for the full data.

General limitations of EST-based strategies, which have been abundantly discussed elsewhere $[4,33,34]$, include poor sequencing depth of the libraries, uncertainty concerning the origin of the samples, and differences in library sizes. In addition, analysis of tumor-related differential expression patterns of individual transcripts may have specific drawbacks. For example, cancer cells often proliferate more rapidly than adjacent normal cells and it is possible that, in some cases, the observed changes in transcript abundance may reflect a response to increased proliferation rather than transformation per se. One related problem is that many cell types are often pooled together during the preparation of EST libraries. Given that most cancers start as growths of single cells, the lack of cell-type specific libraries is a major limiting factor of the method. Lastly, the determined variations in transcript expression may not correlate with similar variations in the abundance of the encoded protein, highlighting the need to experimentally test the computer-based predictions either by western blotting or immunohistochemistry. Our validation result showing that $\mathrm{Bcl}-\mathrm{xL}$ protein expression was markedly increased in hepatocellular carcinoma and 


\begin{tabular}{|c|c|c|c|}
\hline Tissue & & Description & $P$ value \\
\hline \multirow{4}{*}{ BLOOD } & \multirow{4}{*}{\begin{tabular}{|l|} 
ENST00000221209 \\
ENST00000296417 \\
ENST00000215071 \\
ENST00000310911 \\
\end{tabular}} & \multirow{4}{*}{$\begin{array}{l}\text { BCL2/adenovirus E1B 19-kDa protein-interacting protein } 3 \text { like (NIP3L) } \\
\text { Histone H2A.z } \\
\text { 26S proteasome non-ATPase regulatory subunit } 8 / \mathrm{S} 14 \\
\text { Neutrophil defensin precursor (HNP-1/2) }\end{array}$} & $1,15 \mathrm{E}-43$ \\
\hline & & & $2,41 \mathrm{E}-28$ \\
\hline & & & $2,21 \mathrm{E}-22$ \\
\hline & & & $3,25 \mathrm{E}-36$ \\
\hline \multirow{4}{*}{ BONE } & \multirow{4}{*}{$\begin{array}{l}\text { ENST00000265131 } \\
\text { ENST00000222271 } \\
\text { ENST00000287603 } \\
\text { ENST00000044462 } \\
\end{array}$} & \multirow{4}{*}{$\begin{array}{l}\text { Tenascin precursor } \\
\text { Cartilage oligomeric matrix protein precursor (COMP) } \\
\text { Prothymosin alpha } \\
\text { Proteasome subunit alpha type } 4 \text { (component C9) } \\
\end{array}$} & $2,14 \mathrm{E}-08$ \\
\hline & & & $4,04 \mathrm{E}-14$ \\
\hline & & & $1,23 \mathrm{E}-09$ \\
\hline & & & $2,73 \mathrm{E}-07$ \\
\hline \multirow{4}{*}{ BRAIN } & \multirow{4}{*}{$\begin{array}{l}\text { ENST00000286452 } \\
\text { ENST00000261918 } \\
\text { ENST00000255029 } \\
\text { ENST00000322395 }\end{array}$} & \multirow{4}{*}{$\begin{array}{l}\text { Neuronal kinesin heavy chain } 1 \text { (NKHC 5A) } \\
\text { Semaphorin 7A precursor (Semaphorin L/K1/CD108) } \\
\text { brevican isoform 1; chondroitin sulfate proteoglycan BEHAB } \\
\text { 14-3-3 protein sigma }\end{array}$} & $3,29 \mathrm{E}-19$ \\
\hline & & & $3,14 \mathrm{E}-53$ \\
\hline & & & $7,14 \mathrm{E}-41$ \\
\hline & & & $1,37 \mathrm{E}-17$ \\
\hline \multirow{4}{*}{ EYE } & \multirow{4}{*}{\begin{tabular}{|l|} 
ENST00000228811 \\
ENST00000252725 \\
ENST00000233084 \\
ENST00000271558
\end{tabular}} & \multirow{4}{*}{$\begin{array}{l}\text { Proline-rich protein } 4 \text { precursor (Lacrimal proline-rich protein) } \\
\text { ARP2/3 complex } 41 \mathrm{kDa} \text { subunit (P41-ARC) } \\
\text { ATP-dependent helicase DDX1 (DEAD-box protein 1) } \\
\text { Retinoic acid-binding protein II, cellular (CRABP-II) }\end{array}$} & $2,50 \mathrm{E}-24$ \\
\hline & & & $6,36 \mathrm{E}-09$ \\
\hline & & & $4,70 \mathrm{E}-22$ \\
\hline & & & $5,63 \mathrm{E}-17$ \\
\hline \multirow{4}{*}{ LIVER } & \multirow{4}{*}{$\begin{array}{l}\text { ENST00000311190 } \\
\text { ENST00000302053 } \\
\text { ENST00000224237 } \\
\text { ENST00000250383 }\end{array}$} & \multirow{4}{*}{$\begin{array}{l}\text { Serum amyloid A protein precursor (SAA) } \\
\text { Fibrinogen alpha/alpha-E chain precursor } \\
\text { Vimentin } \\
\text { Dehydrogenase/reductase SDR family member } 2 \text { (HEP27 protein) }\end{array}$} & $2,58 \mathrm{E}-88$ \\
\hline & & & $5,52 \mathrm{E}-116$ \\
\hline & & & $3,32 \mathrm{E}-22$ \\
\hline & & & $1,93 \mathrm{E}-21$ \\
\hline \multirow{4}{*}{ LUNG } & \multirow{4}{*}{\begin{tabular}{|l|} 
ENST00000276297 \\
ENST00000263228 \\
ENST00000310118 \\
ENST00000311218
\end{tabular}} & \multirow{4}{*}{$\begin{array}{l}\text { Rho-GTPase-activating protein } 7 \text { (Dlc-1) } \\
\text { ubiquitin-conjugating enzyme UBC3B } \\
26 S \text { proteasome non-ATPase regulatory subunit } 2 \\
\text { NULL (60S RIBOSOMAL L29 IPRO02673 Ribosomal L29e protein) }\end{array}$} & $1,33 \mathrm{E}-18$ \\
\hline & & & $2,05 E-50$ \\
\hline & & & $1,01 \mathrm{E}-09$ \\
\hline & & & $1,54 \mathrm{E}-07$ \\
\hline \multirow{4}{*}{ LYMPH } & ENST00000332976 & Wolf-Hirschhorn syndrome candidate 1 protein isoform 1 & $4,48 \mathrm{E}-15$ \\
\hline & ENST00000304187 & Ig kappa chain V-III region CLL precursor (Rheumatoid factor) & $6,01 \mathrm{E}-11$ \\
\hline & ENST00000263737 & Tetratricopeptide repeat protein 7 (TPR repeat protein 7 ) & $5,61 \mathrm{E}-10$ \\
\hline & ENST00000175506 & Asparagine synthetase (TS11 cell cycle control protein) & $7,31 \mathrm{E}-09$ \\
\hline & ENST00000326227 & Macrophage metalloelastase precursor (MMP-12) & $1,08 \mathrm{E}-15$ \\
\hline & ENST00000295522 & Claudin-1 & $6,37 \mathrm{E}-21$ \\
\hline IMAIVIMARY GLAND & ENST00000323803 & SAM pointed domain containing Ets transcription factor & $1,23 \mathrm{E}-30$ \\
\hline & ENST00000323636 & MTO1 protein homolog (CGI-02) & $6,75 \mathrm{E}-16$ \\
\hline & ENST00000309889 & Telethonin (Titin cap protein) & $4,36 \mathrm{E}-37$ \\
\hline MUSCLE & ENST00000291901 & Troponin $\mathrm{T}$ & $1,42 \mathrm{E}-82$ \\
\hline IVIUSCLE & ENST00000250003 & Myoblast determination protein 1 (Myogenic factor 3 ) & $1,43 \mathrm{E}-22$ \\
\hline & ENST00000303887 & DNA replication licensing factor MCM7 (CDC47 homolog) & $6,87 \mathrm{E}-18$ \\
\hline & ENST00000222543 & Tissue factor pathway inhibitor 2 precursor (Placental protein 5) & $7,80 \mathrm{E}-101$ \\
\hline PI ACENTA & ENST00000301408 & Choriogonadotropin beta chain precursor (CG-beta) & $2,75 \mathrm{E}-21$ \\
\hline PLACENIA & ENST00000268664 & $40 S$ ribosomal protein S2 (S4) (LLREP3 protein) & $7,02 \mathrm{E}-156$ \\
\hline & ENST00000270172 & DNA (cytosine-5)-methyltransferase 3-like & $1,71 \mathrm{E}-15$ \\
\hline & ENST00000310212 & Tubulin tyrosine ligase-like protein HOTTL (HQP0207) & $1,23 \mathrm{E}-37$ \\
\hline PROSTATF & ENST00000296755 & Microtubule-associated protein 1B (MAP 1B) & $3,33 \mathrm{E}-30$ \\
\hline PRUSIAIE & ENST00000262030 & ATP synthase beta chain, mitochondrial precursor & $4,81 \mathrm{E}-07$ \\
\hline & ENST00000315127 & NULL (IPR004443 YjeF-related protein) & $1,91 \mathrm{E}-15$ \\
\hline & ENST00000289906 & Apolipoprotein A-II precursor (Apo-AII) (ApoA-II) & $5,73 \mathrm{E}-29$ \\
\hline & ENST00000323496 & thymosin-like 6 & $2,14 \mathrm{E}-66$ \\
\hline SKIN & ENST00000329835 & Melanocyte protein Pmel 17 precursor (ME20M/ME20S antigen) & $5,10 \mathrm{E}-66$ \\
\hline & ENST00000331803 & Uridine phosphorylase 1 & $2,94 \mathrm{E}-09$ \\
\hline & ENST00000264498 & Heparin-binding growth factor 2 precursor (HBGF-2/BFGF) & $7,90 \mathrm{E}-28$ \\
\hline STOMACH & ENST00000238983 & Triacylglycerol lipase, gastric precursor & $3,12 \mathrm{E}-118$ \\
\hline SIVIVIACA & ENST00000216281 & Heat shock protein HSP 90-alpha (HSP 86) & $1,57 \mathrm{E}-15$ \\
\hline & ENST00000215631 & Growth arrest and DNA-damage-inducible protein GADD45 beta & $3,25 \mathrm{E}-15$ \\
\hline & ENST00000312511 & Sperm protamine P1 (Cysteine-rich protamine) & $1,15 \mathrm{E}-39$ \\
\hline & ENST00000304434 & homolog of yeast polyunsaturated fatty acid elongation enzyme 2 & $7,82 \mathrm{E}-15$ \\
\hline TE & ENST00000311135 & BLOCK 23 & $1,99 \mathrm{E}-33$ \\
\hline & ENST00000322819 & zinc finger, $\mathrm{CCHC}$ domain containing 7 & $4,41 \mathrm{E}-10$ \\
\hline
\end{tabular}

Figure 3

Genes whose transcripts exhibited tissue-specific differential expression in normal versus tumor libraries. This figure is a compilation of genes that appear to be differentially expressed in only one of the I5 studied tissues. The results are shown for fourteen tissues. The color code is the same as in Figure I. See additional information for the full data. 


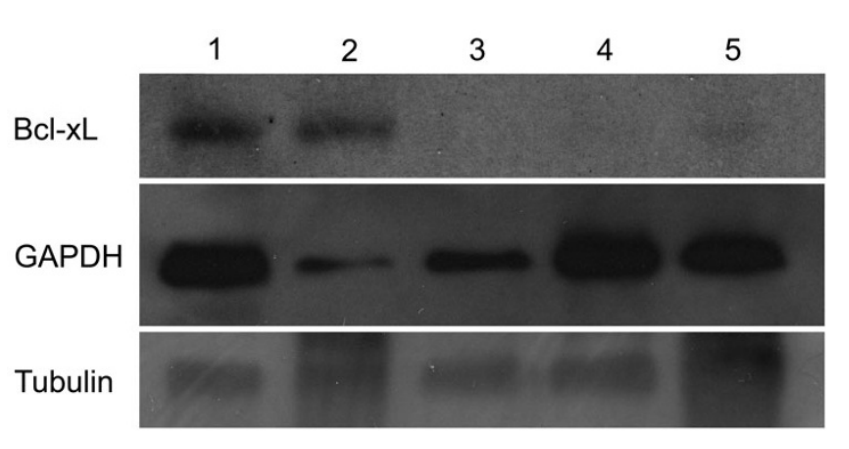

Figure 4

Western blot analysis of $\mathrm{Bcl}-\mathbf{x L}$ expression in human normal and tumoral liver. Lane $\mathrm{I}$ : hepatocellular carcinoma (male, age 65); lane 2: adenocarcinoma (male, age 52); lane 3: cholangiocellular carcinoma (male, age 46); lane 4: normal liver (male, age 24); lane 5: normal placenta (female, age 24). Bcl-xL immunoreactivity (26 kD) was observed in two out of three liver cancer samples (lanes I-3). Normal samples (lane 4-5) had no signal for $\mathrm{Bcl}-\mathrm{xL}$ expression. Note that GADPH protein levels varied between normal tissues and cancer liver specimens and did not correlate with the mRNA levels predicted by the computer-based screen. The expression of tubulin was used as control for equal protein loading.

liver adenocarcinoma suggests that this Bcl-2 family member represent a potential marker for progression of a subset of liver cancers. Analysis of Bcl-xL immunoreactivity in more liver cancer specimens is needed to enhance the reliability of this finding. However, as it correlates with previous results [35-37], and in view of the pro-survival effect of Bcl-xL, we hypothesize that Bcl-xL overexpression could confer specific protection from death to several types of liver cancer cells compared to their healthy counterparts. If true, modulation of Bcl-xL expression level and/or activity might represent an interesting strategy to optimize the efficacy of chemotherapeutic agents in this particular tissue, as liver cancer represents a significant source of morbidity and mortality worldwide [38].

Aside from the proposal of potential diagnosis markers and targets for future cancer research, a more theoretical perspective of our study is the identification of critical factors that could influence differential gene expression levels in normal versus cancer cells, including genomic landscape features, e.g. levels of polymorphisms, chromosome breakpoints, gene density, GC content and chromatin methylation status. In this regard, although we cannot rule out the possibility of unidentified biases in our data mining procedure, our result showing a higher frequency of gene inactivation patterns in tumor tissues is intriguing, and sheds light on the importance of understanding the molecular mechanisms of negative gene regulation in cancer.

\section{Conclusion}

The final outcomes of the present work are identification of chromosomal regions frequently associated with aberrant expression in cancer libraries, description of differential expression profiles, and listing of cancer candidate genes (e.g. Bcl-xL) which may be useful as tissue-specific biomarkers for cancer diagnosis or as targets for anticancer research.

\section{Methods \\ Data preparation}

We have used an EST-based pipeline to scan for differential gene expression levels between normal and tumor states. Human ESTs from dbEST [39] (October 2004 release) were first extracted using the ACNUC sequence retrieval system [40]. ESTs were classified according to their UNIGENE library features [41] (October 2004). For each EST in dbEST, we extracted the accession code of the EST and the tissue or organ from which the EST library has been made. The tissue type was retrieved from the line containing 'Tissue_type', 'Tissue description', 'Organ' or 'Keyword'. This parsing approach stored no data when the tissue information did not appear in these fields, or in case of typographical errors or ambiguous aliases. ESTs that were labeled as coming from an unspecified tissue (e.g. 'mixed', 'pooled organs', 'cell line') or from a mixture of specified tissues, were discarded. The eVOC ontology [42] (October 2004) for anatomical sites and pathology types was then used to classify the libraries through a number of criteria such as tissue origin and pathological context including tumor state. This well-accepted hierarchical vocabulary provided us with a mean to determine when a specific tissue was part of an organ and when a specific label was part of the 'tumoral' state. A total of 5135 'tumor' and 2503 'normal' (i.e. non-pathological) libraries were catalogued. Our approach to EST clustering used the human genome as a reliable guide. ENSEMBL RNAs [43] annotated on human genome assembly (release 16.3) were used as a backbone for the clustering of dbEST sequences using MEGABLAST (alignment length $=100 \mathrm{bp}$ and similarity $=95 \%$ ) [44]. In order to avoid paralogous false positive assignation, only best EST hit matches were subsequently selected. RNA clustering of ESTs in both normal and tumor tissues was the starting point for digital differential analysis of gene expression.

\section{Computer-based differential display procedure}

The cDNA libraries were categorized into non-normalized or normalized/subtracted libraries by screening for the appropriate keywords in the original annotation of the respective dbEST entries (in the 'Keyword' and 'Library treatment' fields). All libraries for which none of the keywords were found were defined as being non-normalized. After removal of normalized and subtracted EST libraries, we created pools of equivalent EST libraries, i.e. libraries 
Table 2: Chromosomal regions of differential gene expression in cancer. (A) Number of hits, i.e. number of genes with differential expression per chromosome, is depicted. 'Up' and 'down' mean chromosomal regions with increased and decreased tumor expression, respectively. '\%' represents the percentage of candidate genes against the total number of genes present on the chromosome. (B) Chromosomal regions found to be associated with at least 5 hits in the digital subtraction analysis are shown ('banding'). '\%' represents the percentage of hits for a particular chromosomal banding against the total number of genes present in the same banding. Chromosomal bandings marked in bold correspond to previously identified regions associated with either tumor amplicon ('Up' column) or deleted ('Down' column) regions in tumors.

\begin{tabular}{|c|c|c|c|c|c|c|c|c|c|c|}
\hline \multirow{3}{*}{$\begin{array}{l}\text { Chromoso } \\
\text { me }\end{array}$} & \multicolumn{6}{|l|}{$\mathbf{A}$} & \multicolumn{4}{|l|}{ B } \\
\hline & $U_{p}$ & & Down & & Up+Down & & Up & & Down & \\
\hline & Total Hits & $\%$ & Total Hits & $\%$ & Total Hits & $\%$ & Banding & $\%$ & Banding & $\%$ \\
\hline I & 33 & 1.02 & 54 & 1.68 & 87 & 2.70 & & & $\begin{array}{l}\text { Iq21.3 } \\
\text { Iq32. I }\end{array}$ & $\begin{array}{l}3.12 \\
3.20\end{array}$ \\
\hline 2 & 11 & 0.75 & 28 & 1.90 & 39 & 2.65 & & & $\begin{array}{l}2 p \mid 1.2 \\
2 p \mid 3.3 \\
2 q 35\end{array}$ & $\begin{array}{l}6.66 \\
9.26 \\
4.55\end{array}$ \\
\hline 3 & 11 & 0.55 & 58 & 2.89 & 69 & 3.43 & $3 p 21.31$ & 4.03 & $3 p 21.31$ & 3.14 \\
\hline 4 & 38 & 2.26 & 46 & 2.73 & 84 & 4.99 & & & $4 q 13.3$ & 9.37 \\
\hline 5 & 4 & 0.67 & 8 & 1.35 & 12 & 2.02 & & & $5 q 33.1$ & 6.58 \\
\hline 6 & 14 & 1.22 & 36 & 3.15 & 50 & 4.37 & 6p21.31 & 6.33 & & \\
\hline 7 & 11 & 1.05 & 19 & 1.81 & 30 & 2.86 & & & $\begin{array}{l}\text { 7q21.3 } \\
7 q 22.1\end{array}$ & $\begin{array}{l}8.93 \\
3.32\end{array}$ \\
\hline 8 & 18 & 1.25 & 30 & 2.08 & 48 & 3.34 & & & & \\
\hline 9 & 31 & 1.69 & 39 & 2.13 & 70 & 3.82 & & & $\begin{array}{l}9 q 34.11 \\
9 q 34.3\end{array}$ & $\begin{array}{l}3.60 \\
3.60\end{array}$ \\
\hline 10 & 5 & 1.05 & 10 & 2.10 & 15 & 3.15 & & & & \\
\hline II & 30 & 1.32 & 46 & 2.03 & 76 & 3.36 & & & $\begin{array}{l}\text { I I }|\mathbf{5} .| \\
\text { I Ip I5.4 } \\
\text { I Ip I5.5 } \\
\text { I | } \mid 2.2\end{array}$ & $\begin{array}{l}7.81 \\
2.56 \\
5.88 \\
7.81\end{array}$ \\
\hline 12 & 25 & 1.14 & 61 & 2.78 & 86 & 3.91 & $\begin{array}{l}12 q 13.13 \\
12 q 13.3\end{array}$ & $\begin{array}{l}4.80 \\
10.12\end{array}$ & $12 q 13.13$ & 7.20 \\
\hline 13 & 19 & 1.76 & 21 & 1.94 & 40 & 3.70 & & & & \\
\hline 14 & 5 & 1.27 & 8 & 2.03 & 13 & 3.29 & $|4 q| 1.2$ & 2.59 & $\begin{array}{l}|4 q||| .2 \\
\mid 4 q 32.33\end{array}$ & $\begin{array}{l}2.59 \\
8.89\end{array}$ \\
\hline 15 & 7 & 0.84 & 16 & 1.93 & 23 & 2.77 & & & & \\
\hline 16 & 19 & 1.08 & 40 & 2.28 & 59 & 3.36 & $|6 p| \mid .2$ & 3.10 & $\begin{array}{l}|6 p| 1.2 \\
|6 q| 2.2\end{array}$ & $\begin{array}{l}3.10 \\
9.80\end{array}$ \\
\hline 17 & 9 & 0.74 & 38 & 3.14 & 47 & 3.88 & $\begin{array}{l}|7 q 2| .2 \\
\mid 7 q 25.3\end{array}$ & $\begin{array}{l}5.71 \\
2.81\end{array}$ & $\begin{array}{l}17 q 21.2 \\
17 q 23.3\end{array}$ & $\begin{array}{l}5.00 \\
8.06\end{array}$ \\
\hline 18 & 12 & 0.86 & 31 & 2.22 & 43 & 3.08 & & & & \\
\hline 19 & 14 & 0.80 & 29 & 1.65 & 43 & 2.44 & $|9 p| 3.3$ & 2.43 & $\begin{array}{l}19 p|3.1| \\
|9 q| 3.2 \\
|9 q| 3.3 \mid \\
|9 q| 3.33\end{array}$ & $\begin{array}{l}2.15 \\
3.69 \\
7.04 \\
3.14\end{array}$ \\
\hline 20 & 10 & 0.56 & 38 & 2.13 & 48 & 2.69 & & & $20 q 13.12$ & 2.92 \\
\hline 21 & 8 & 0.70 & 25 & 2.18 & 33 & 2.87 & 21 q22.3 & 3.12 & $21 \mathrm{q} 22.3$ & 3.75 \\
\hline 22 & 17 & 1.20 & 31 & 2.19 & 48 & 3.40 & & & & \\
\hline$x$ & 21 & 1.59 & 31 & 2.34 & 52 & 3.93 & Xq28 & 4.76 & & \\
\hline Y & 1 & 0.64 & 1 & 0.64 & 2 & 1.27 & & & & \\
\hline
\end{tabular}

derived from the same tissue type and state (normal and tumor). Differential screening analysis was accomplished for a considered tissue when both normal and tumor pools displayed at least 10,000 ESTs. A total of 15 distinct paired tissue pools (blood, bone, brain, colon, eye, liver, lung, lymph, mammary gland, muscle, placenta, prostate, skin, stomach, testis) representing approximately 1.5 mil- lion ESTs were therefore retained for the whole genome screening. Differential screening was performed for each tissue type individually using EST counts from tumors and corresponding normal counterparts. The relative expression of one particular gene in a tissue was characterized by the ratio of the number of ESTs matching this gene to the total number of ESTs sequenced in the respective tissue. 
As such 'gene expression profiles' were derived from 'normal' and 'tumor' libraries, it was possible to build $2 \times 2$ contingency tables and then to apply the Fisher exact test against the null hypothesis that there was no association between a particular gene and the tumoral state. A $p$-value was determined for statistical significance and, because multiple tests were performed, a Bonferroni correction was applied on each pairs in order to reduce the false positive rate and to perform candidate gene sorting. Statistically significant hits showing at least 10-fold differences were compiled. Four classes of genes were defined, namely (i) genes displaying significantly higher expression levels in tumor tissues ('up-regulated' genes); (ii) genes displaying significantly lower expression levels in tumor tissues ('down-regulated' genes); (iii) genes expressed in tumor but not in normal tissues ('tumor-specific' genes); (iv) genes absent in the tumor types compared to normal tissues. Apart from the genes displaying absolute differences between normal and tumor condition, a ratio based on EST abundance in both conditions was computed to estimate the expression fold change for up- and down-regulated genes. Cytogenetic map position of the hits was inferred using ENSEMBL data (release 16.3). The pattern of expression of the differentially expressed transcripts $(n=1190$, as determined by the EST analysis) in normal tissues was independently assessed by comparison to SAGE results obtained on the SAGE Genie website [45] and processed as previously described [46]. A total of 141 (non-tumoral) libraries containing more than 20,000 tags were partitioned into 19 normal tissues. The expression pattern of 13,435 transcripts was determined. Eight tissues (blood, brain, colon, liver, lung, mammary gland, placenta and prostate) were unambiguously mapped to the tissue terms used in the EST data mining procedure. From this sample, we queried as to which candidate transcripts associated with differential expression in a particular tissue (on the basis of the EST predictions) was expressed in the corresponding normal tissue (according to the SAGE data). Information on differential expression was also gained from reference to primary literature. As this effort corresponded to a manual task particularly unfitted to the large number of candidate genes presented here, we limited the analysis to the "up-regulated" and "down-regulated" lists related to the liver and breast tissues. We found that $54.2 \%$ (for liver) and $41.7 \%$ (for breast) of the annotated candidates identified through our computer-based screen were consistent with previously published data (see Additional files 1 and 3). The differential display procedure and other analytical steps were developed with $\mathrm{R}$ [47]. Expression and genomic data were stored in a local PostgreSQL database (GeMCore) [48] using PERL and Java script.

\section{Western blot analysis}

Nitrocellulose membrane was from Euromedex (Souffelweyersheim, France). The membrane was immunoblotted with anti-human Bcl-xL antibody (1:1 000 dilution, BD Pharmingen), and then with anti-mouse IgG antibody conjugated to horseradish peroxidase (1:5 000 dilution, Dako). Protein bands were revealed using enhanced chemiluminescence kit (ECL, Amersham). The membrane was stripped according to manufacturer's instructions and reprobed with anti-glyceraldehyde-3-phosphate dehydrogenase (GAPDH) monoclonal antibody (1:1 000 dilution) and with anti-alpha-tubulin (1:1000 dilution, Sigma) to correct for differences in protein loading.

\section{Authors' contributions}

AA designed the study, performed the immunoblot assays, analyzed the data and drafted the manuscript. VN developed the algorithm for the differential display procedure, processed the SAGE data, participated in the data analyses and reviewed the manuscript. $\mathrm{AB}$ provided the antibodies and participated in the western blotting experiments. DM and CG provided funding and supervision for the work. All authors read and approved the final manuscript.

\section{Additional material}

\section{Additional File 1}

Upregulated candidates complete list. Upregulated genes in tumor tissues (complete list). Hits displaying at least a 10-fold increase in tumorderived libraries compared to their normal tissue counterpart are shown. Chromosomal locations for each hit were inferred from Ensembl cytogenetic map. Hits were sorted by $p$ value (exact Fisher's test; $\mathrm{p}<0.05$, Bonferroni corrected), ranked by expression ratio and ordered by tissue. Both known and novel ('NULL') transcripts are listed. 'Y': 'Yes'; 'ND': nondetermined. Pubmed ID (PMID) is given for annotated candidate transcripts whose differential expression was documented in previously published data. '*': in silico studies.

Click here for file

[http://www.biomedcentral.com/content/supplementary/14712164-7-94-S1.xls]

\section{Additional File 2}

Downregulated candidates complete list. Downregulated genes in tumor tissues (complete list). Hits displaying at least a 10-fold decrease in tumor-derived libraries compared to their normal tissue counterpart are shown. Chromosomal locations for each hit were inferred from Ensembl cytogenetic map. Hits were sorted by p value (exact Fisher's test; $\mathrm{p}<0.05$, Bonferroni corrected), ranked by expression ratio and ordered by tissue. Both known and novel ('NULL') transcripts are listed. 'Y': 'Yes'; 'ND': non-determined. Pubmed ID (PMID) is given for annotated candidate transcripts whose differential expression was documented in previously published data. '*': in silico studies.

Click here for file

[http://www.biomedcentral.com/content/supplementary/14712164-7-94-S2.xls]

\section{Additional File 3}


Tumor specific candidates complete list. Complete list of genes absent from normal tissues and present in tumor types. Tumor-specific hits are shown. Chromosomal locations for each hit were inferred from Ensembl cytogenetic map. Hits were sorted by $p$ value (exact Fisher's test; $\mathrm{p}<0.05$, Bonferroni corrected) and ranked by tissue origin. Both known and novel ('NULL') transcripts are listed. 'Y': 'Yes'; 'ND': non-determined. Click here for file [http://www.biomedcentral.com/content/supplementary/14712164-7-94-S3.xls]

\section{Additional File 4}

Normal specific candidates complete list. Summary of genes absent from tumor types and present in normal tissues. Genes absent in the tumor types compared to normal tissues is shown. Chromosomal locations for each hit were inferred from Ensembl cytogenetic map. Hits were sorted by $p$ value (exact Fisher's test; $\mathrm{p}<0.05$, Bonferroni corrected) and ranked by tissue origin. Both known and novel ('NULL') transcripts are listed. 'Y': 'Yes'; 'ND': non-determined.

Click here for file

[http://www.biomedcentral.com/content/supplementary/14712164-7-94-S4.xls]

\section{Additional File 5}

Consistent candidates in multiple tissues. Genes whose transcripts varied significantly and consistently in abundance in at least two different tissues.

Click here for file

[http://www.biomedcentral.com/content/supplementary/1471-

2164-7-94-S5.xls]

\section{Additional File 6}

Tissue specific candidates. Genes whose transcripts exhibited tissue-specific differential expression in normal versus tumor libraries.

Click here for file

[http://www.biomedcentral.com/content/supplementary/14712164-7-94-S6.xls]

\section{Acknowledgements}

VN is supported by a grant from INRA. AA is recipient of a fellowship from the ARC. The authors wish to thank Sandy Jacquier for critical reading of the manuscript, Dr. Pierre Colas at Aptanomics for providing the anti-Bcl$x \mathrm{~L}$ antibody and Dr. Cyrile Lamigeon for the anti-GAPDH antibody. We are grateful to Dr. Marie Semon for sharing the SAGE data.

\section{References}

I. Gray JW, Collins C: Genome changes and gene expression in human solid tumors. Carcinogenesis 2000, 2 I (3):443-452.

2. Rajkovic A, Yan MSC, Klysik M, Matzuk M: Discovery of germ cellspecific transcripts by expressed sequence tag database analysis. Fertil Steril 200I, 76(3):550-554.

3. Wang J, Liang P: DigiNorthern, digital expression analysis of query genes based on ESTs. Bioinformatics 2003, 19(5):653-654.

4. Schmitt AO, Specht T, Beckmann G, Dahl E, Pilarsky CP, Hinzmann $B$, Rosenthal A: Exhaustive mining of EST libraries for genes differentially expressed in normal and tumour tissues. Nucleic Acids Res 1999, 27(2I):425I-4260.

5. Lal A, Lash AE, Altschul SF, Velculescu V, Zhang L, McLendon RE, Marra MA, Prange C, Morin PJ, Polyak K, Papadopoulos N, Vogelstein B, Kinzler KW, Strausberg RL, Riggins G]: A public database for gene expression in human cancers. Cancer Res 1999, 59(21):5403-5407.

6. Dahl E, Sadr-Nabavi A, Klopocki E, Betz B, Grube S, Kreutzfeld R, Himmelfarb M, An HX, Gelling S, Klaman I, Hinzmann B, Kristiansen G, Grutzmann R, Kuner R, Petschke B, Rhiem K, Wiechen K, Sers C,
Wiestler O, Schneider A, Hofler H, Nahrig J, Dietel M, Schafer R, Rosenthal A, Schmutzler R, Durst M, Meindl A, Niederacher D: Systematic identification and molecular characterization of genes differentially expressed in breast and ovarian cancer. J Pathol 2005, 205(I):2I-28

7. Grutzmann R, Pilarsky C, Staub E, Schmitt AO, Foerder M, Specht T, Hinzmann B, Dahl E, Alldinger I, Rosenthal A, Ockert D, Saeger HD: Systematic isolation of genes differentially expressed in normal and cancerous tissue of the pancreas. Pancreatology 2003 , 3(2): $169-178$

8. Scheurle D, DeYoung MP, Binninger DM, Page H, Jahanzeb M, Narayanan R: Cancer gene discovery using digital differential display. Cancer Res 2000, 60( 15 ):4037-4043.

9. Baranova AV, Lobashev AV, Ivanov DV, Krukovskaya LL, Yankovsky NK, Kozlov AP: In silico screening for tumour-specific expressed sequences in human genome. FEBS Lett 200I, 508(I): $143-148$.

10. Brentani H, Caballero OL, Camargo AA, da Silva AM, da Silva WA Jr. Dias Neto E, Grivet M, Gruber A, Guimaraes PE, Hide W, Iseli C, Jongeneel CV, Kelso J, Nagai MA, Ojopi EP, Osorio EC, Reis EM, Riggins GJ, Simpson AJ, de Souza S, Stevenson BJ, Strausberg RL, Tajara EH, Verjovski-Almeida S, Acencio ML, Bengtson MH, Bettoni F, Bodmer WF, Briones MR, Camargo LP, Cavenee W, Cerutti JM, Coelho Andrade LE, Costa dos Santos PC, Ramos Costa MC, da Silva IT, Estecio MR, Sa Ferreira K, Furnari FB, Faria M Jr, Galante PA, Guimaraes GS, Holanda AJ, Kimura ET, Leerkes MR, Lu X, Maciel RM, Martins EA, Massirer KB, Melo AS, Mestriner CA, Miracca EC, Miranda LL, Nobrega FG, Oliveira PS, Paquola AC, Pandolfi JR, Campos Pardini MI, Passetti F, Quackenbush J, Schnabel B, Sogayar MC, Souza JE, Valentini SR, Zaiats AC, Amaral EJ, Arnaldi LA, de Araujo AG, de Bessa SA, Bicknell DC, Ribeiro de Camaro ME, Carraro DM, Carrer H, Carvalho AF, Colin C, Costa F, Curcio C, Guerreiro da Silva ID, Pereira da Silva N, Dellamano M, El-Dorry H, Espreafico EM, Scattone Ferreira AJ, Ayres Ferreira C, Fortes MA, Gama AH, Giannella-Neto D, Giannella ML, Giorgi RR, Goldman GH, Goldman MH, Hackel C, Ho PL, Kimura EM, Kowalski LP, Krieger JE, Leite LC, Lopes A, Luna AM, Mackay A, Mari SK, Marques AA, Martins WK, Montagnini A, Mourao Neto M, Nascimento AL, Neville AM, Nobrega MP, O'Hare MJ, Otsuka AY, Ruas de Melo Al, Paco-Larson ML, Guimaraes Pereira G, Pesquero JB, Pessoa JG, Rahal P, Rainho CA, Rodrigues V, Rogatto SR, Romano CM, Romeiro JG, Rossi BM, Rusticci M, Guerra de Sa R, Sant' Anna SC, Sarmazo ML, Silva TC, Soares FA, Sonati Mde F, de Freitas Sousa J, Queiroz D, Valente V, Vettore AL, Villanova FE, Zago MA, Zalcberg $\mathrm{H}$ : The generation and utilization of a cancer-oriented representation of the human transcriptome by using expressed sequence tags. Proc Natl Acad Sci U S A 2003, 100(23): I34|8-13423.

II. Aouacheria A, Navratil V, Wen W, jiang M, Mouchiroud D, Gautier C, Gouy M, Zhang M: In silico whole-genome scanning of cancer-associated nonsynonymous SNPs and molecular characterization of a dynein light chain tumour variant. Oncogene 2005, 24(40):6|33-6|42.

12. Du W, Lebowitz PF, Prendergast GC: Elevation of alpha2(I) collagen, a suppressor of Ras transformation, is required for stable phenotypic reversion by farnesyltransferase inhibitors. Cancer Res 1999, 59(9):2059-2063.

13. Andreu T, Beckers T, Thoenes E, Hilgard P, von Melchner H: Gene trapping identifies inhibitors of oncogenic transformation. The tissue inhibitor of metalloproteinases-3 (TIMP3) and collagen type I alpha2 (COLIA2) are epidermal growth factor-regulated growth repressors. I Biol Chem 1998, 273(22): | 3848- | 3854.

14. Moll R: Cytokeratins in the histological diagnosis of malignant tumors. Int J Biol Markers 1994, 9(2):63-69.

15. Jiang Y, Harlocker SL, Molesh DA, Dillon DC, Stolk JA, Houghton RL, Repasky EA, Badaro R, Reed SG, Xu J: Discovery of differentially expressed genes in human breast cancer using subtracted cDNA libraries and cDNA microarrays. Oncogene 2002, 2I(14):2270-2282.

16. Holland EC, Sonenberg N, Pandolfi PP, Thomas G: Signaling control of mRNA translation in cancer pathogenesis. Oncogene 2004, 23( I 8):3। 38-3|44.

17. Ruggero D, Grisendi S, Piazza F, Rego E, Mari F, Rao PH, CordonCardo C, Pandolfi PP: Dyskeratosis congenita and cancer in mice deficient in ribosomal RNA modification. Science 2003 299(5604):259-262. 
18. Bader AG, Vogt PK: An essential role for protein synthesis in oncogenic cellular transformation. Oncogene 2004, 23(I8):3|45-3|50.

19. Lai J, Flanagan J, Phillips WA, Chenevix-Trench G, Arnold J: Analysis of the candidate 8p2I tumour suppressor, BNIP3L, in breast and ovarian cancer. $\mathrm{Br}$ J Cancer 2003, 88(2):270-276.

20. Matsushima M, Fujiwara T, Takahashi E, Minaguchi T, Eguchi Y, Tsujimoto $Y$, Suzumori $K$, Nakamura $Y$ : Isolation, mapping, and functional analysis of a novel human cDNA (BNIP3L) encoding a protein homologous to human NIP3. Genes Chromosomes Cancer 1998, 2 I (3):230-235.

21. Rountree MR, Bachman KE, Herman JG, Baylin SB: DNA methylation, chromatin inheritance, and cancer. Oncogene 200I, 20(24):3156-3165.

22. Robertson KD: DNA methylation and chromatin - unraveling the tangled web. Oncogene 2002, 2 I (35):536I-5379.

23. Wikman $H$, Nymark $P$, Vayrynen A, Jarmalaite $S$, Kallioniemi A, Salmenkivi K, Vainio-Siukola K, Husgafvel-Pursiainen K, Knuutila S, Wolf $M$, Anttila S: CDK4 is a probable target gene in a novel amplicon at I 2q | 3.3-q I 4. I in lung cancer. Genes Chromosomes Cancer 2005, 42(2):193-199.

24. Elkahloun AG, Krizman DB, Wang Z, Hofmann TA, Roe B, Meltzer PS: Transcript mapping in a 46-kb sequenced region at the core of $12 \mathrm{q} \mid 3.3$ amplification in human cancers. Genomics 1997, 42(2):295-301.

25. Moskaluk CA, Rumpel CA: Allelic deletion in IIpI5 is a common occurrence in esophageal and gastric adenocarcinoma. Cancer 1998, 83(2):232-239.

26. Scelfo RA, Schwienbacher C, Veronese A, Gramantieri L, Bolondi L, Querzoli P, Nenci I, Calin GA, Angioni A, Barbanti-Brodano G, Negrini M: Loss of methylation at chromosome I/pI5.5 is common in human adult tumors. Oncogene 2002 2I(16):2564-2572.

27. Hammarstrom S: The carcinoembryonic antigen (CEA) family: structures, suggested functions and expression in normal and malignant tissues. Semin Cancer Biol 1999, 9(2):67-8I.

28. Beckers JF, Zarrouk A, Batalha ES, Garbayo JM, Mester L, Szenci O: Endocrinology of pregnancy: chorionic somatomammotropins and pregnancy-associated glycoproteins: review. Acta Vet Hung 1998, 46(2): 175-189.

29. Strausberg RL, Simpson AJ, Wooster R: Sequence-based cancer genomics: progress, lessons and opportunities. Nat Rev Genet 2003, 4(6):409-418.

30. Ghadersohi A, Sood AK: Prostate epithelium-derived Ets transcription factor mRNA is overexpressed in human breast tumors and is a candidate breast tumor marker and a breast tumor antigen. Clin Cancer Res 200I, 7(9):273I-2738.

31. Mitas M, Mikhitarian K, Hoover L, Lockett MA, Kelley L, Hill A, Gillanders WE, Cole DJ: Prostate-Specific Ets (PSE) factor: a novel marker for detection of metastatic breast cancer in axillary lymph nodes. Br J Cancer 2002, 86(6):899-904.

32. Katayama S, Nakayama T, Ito M, Naito S, Sekine I: Expression of the ets-I proto-oncogene in human breast carcinoma: differential expression with histological grading and growth pattern. Histol Histopathol 2005, 20(I): I 19-126.

33. Imyanitov EN, Togo AV, Hanson KP: Searching for cancer-associated gene polymorphisms: promises and obstacles. Cancer Lett 2004, 204(I):3-14.

34. Qiu P, Wang L, Kostich M, Ding W, Simon JS, Greene JR: Genome wide in silico SNP-tumor association analysis. BMC Cancer 2004, 4(I):4.

35. Garcia EJ, Lawson D, Cotsonis G, Cohen C: Hepatocellular carcinoma and markers of apoptosis (bcl-2, bax, bcl-x): prognostic significance. Appl Immunohistochem Mol Morphol 2002, 10(3):210-217.

36. Takehara T, Liu X, Fujimoto J, Friedman SL, Takahashi H: Expression and role of $\mathrm{Bcl}-\mathrm{xL}$ in human hepatocellular carcinomas. Hepatology 200I, 34(I):55-6I.

37. Watanabe J, Kushihata F, Honda K, Sugita A, Tateishi N, Mominoki K, Matsuda S, Kobayashi N: Prognostic significance of Bcl-xL in human hepatocellular carcinoma. Surgery 2004, 135(6):604-6/2

38. Guyton KZ, Kensler TW: Prevention of liver cancer. Curr Oncol Rep 2002, 4(6):464-470.

39. DbEST: Expressed Sequence Tags database [http:// www.ncbi.nlm.nih.gov/dbEST/]
40. Gouy M, Gautier C, Attimonelli M, Lanave C, di Paola G: ACNUC a portable retrieval system for nucleic acid sequence databases: logical and physical designs and usage. Comput Appl Biosci 1985, I(3):167-172.

4I. Unigene: organized view of the transcriptome [ftp:// ftp.ncbi.nih.gov/repository/UniGene/]

42. Evoke: expression ontology toolkit [http://www.egenetics.com/ evoke.html]

43. Ensembl database [http://www.ensembl.org/]

44. Altschul SF, Madden TL, Schaffer AA, Zhang J, Zhang Z, Miller W, Lipman DJ: Gapped BLAST and PSI-BLAST: a new generation of protein database search programs. Nucleic Acids Res 1997, 25(I7):3389-3402.

45. Liang P: SAGE Genie: a suite with panoramic view of gene expression. Proc Natl Acad Sci U S A 2002, 99( I 8): I I 547- I I 548

46. Semon M, Mouchiroud D, Duret L: Relationship between gene expression and GC-content in mammals: statistical significance and biological relevance. Hum Mol Genet 2005, 14(3):421-427.

47. The Comprehensive R Archive Network [http://stat.cmu.edu/ R/CRAN/]

48. GeM (Genomic Mapping) Website [http://pbil.univ-lyonl.fr/ gem/gem home.php]
Publish with Biomed Central and every scientist can read your work free of charge

"BioMed Central will be the most significant development for disseminating the results of biomedical research in our lifetime. "

Sir Paul Nurse, Cancer Research UK

Your research papers will be:

- available free of charge to the entire biomedical community

- peer reviewed and published immediately upon acceptance

- cited in PubMed and archived on PubMed Central

- yours - you keep the copyright

Submit your manuscript here:

http://www.biomedcentral.com/info/publishing_adv.asp
BioMedcentral 